\title{
Article
}

Mycosphere

Doi 10.5943/mycosphere/7/5/1

Copyright (C) Guizhou Academy of Agricultural Sciences

\section{Cultural studies of Psilocybe sensu lato species (Agaricales, Strophariaceae)}

\author{
Silva PS ${ }^{1}$, Guzmán-Dávalos $\mathrm{L}^{2}$ and Silveira RMB $^{1}$ \\ ${ }^{1}$ Universidade Federal do Rio Grande do Sul, Avenida Bento Gonçalves, 9500, CP 91501-970, Porto Alegre, Rio \\ Grande do Sul, Brazil; pulisant@yahoo.com.br \\ ${ }^{2}$ Universidad de Guadalajara, Apartado Postal 1-139, Zapopan, Jalisco, 45101, Mexico.
}

Silva PS, Guzmán-Dávalos L, Silveira RMB 2016 - Cultural studies of Psilocybe sensu lato species (Agaricales, Strophariaceae). Mycosphere 7(5), 531-544, Doi 10.5943/mycosphere/7/5/1

\begin{abstract}
In searching for additional taxonomic characters, cultural characteristics of five strains belonging to five different species of Psilocybe s.l. were studied. A strain of Stropharia venusta was included for comparison. Some macro and micromorphological characteristics, such as growth rate, mat texture, mycelial cystidia and some hyphae modifications may be useful as taxonomic characters. Cultural characters of Deconica horizontalis, D. neorhombispora and S. venusta are described for the first time.
\end{abstract}

Key words - Deconica - mycelia cystidia - strains

\section{Introduction}

Culture characters have been applied by several researchers, especially for characterization of fungi of economic and biotechnological interest, including wood-rotting, edible and medicinal fungi (Stalpers 1978, Buchalo 1988, Stamets 2000). Nobles (1965) stated that some morphological characters of vegetative mycelium may be helpful for taxonomic purposes, and since then, several works have corroborated this idea (Jacobsson 1989, Molitoris et al. 1996, Fausto-Guerra et al. 2002, Buchalo et al. 2011).

Formerly, Psilocybe (Fr.) P. Kumm. included psychotropic and non-psychotropic species, but recently Psilocybe s.str. and Deconica (W. G. Sm.) P. Karst. have been segregated, due the presence of hallucinogenic alkaloids in the first and the absence in the second (Moncalvo et al. 2002). Psilocybe sensu lato comprises saprobic species, growing on soil, decayed wood, logs, stems, and manure (Singer 1986). Some works have already described cultural characters of Psilocybe sensu lato species (Gilmore 1926, Heim et al. 1957, Heim et al. 1963, Dubovoy \& Herrera 1967, Dubovoy \& Herrera 1968, Watling 1971, Buchalo et al. 2009). Walther \& Wei $\beta$ (2008) characterized several Strophariaceae species in culture, including four Psilocybe sensu lato strains, providing taxonomically relevant characters.

In this work we present descriptions of five species belonging to Psilocybe sensu lato, four belonging to Deconica and one belonging to Psilocybe, with macro and micromorphological data, aiming to complement the traditional taxonomy based on basidiome features. 


\section{Materials \& Methods}

Five Psilocybe sensu lato strains were used: Deconica coprophila (Bull.) P. Karst. (P.S. Silva 202/09), D. horizontalis (Bull.) Noordel. (P.S. Silva 253/10), D. neorhombispora (Guzmán) P.S. Silva \& Ram.-Cruz (P.S. Silva 238/09), Deconica sp. (P.S. Silva 235/09) and Psilocybe cubensis (Earle) Singer (P.S. Silva 200/09). Stropharia venusta P.S. Silva, Cortez \& R.M. Silveira (P.S. Silva 265/12) was included for comparison. All collections are from Brazil. Fruit bodies from which the strains were obtained are deposited at herbarium ICN, from Universidade Federal do Rio Grande do Sul, and its corresponding strains are deposited at "Laboratório de Micologia Molecular" at the same university.

For morphological characterization, the strains were grown on Difco Malt Extract Agar (MEA) and incubated at $25{ }^{\circ} \mathrm{C}$ in complete darkness, following procedures indicated by Nobles (1965). The parameters observed were those described by Nobles (1965), with some modifications. Growth rate was evaluated as the percentage of the Petri dish covered in one week (seven days) after inoculating the plate in the center. The macro- and micromorphological characterizations were made every week, during six weeks. Micromorphological observations were made in light microscope, from material mounted in $3 \%$ potassium hydroxide $(\mathrm{KOH})$ and $1 \%$ floxine.

\section{Results}

\section{Cultures descriptions}

Deconica coprophila (Bull.) P. Karst.

Figs $1,7 \mathrm{a}-\mathrm{k}$

Macromorphological characters $-43 \%$ of plate covered by the $7^{\text {th }}$ day (plates not covered in the six weeks, reaching $88 \%$ in the last week); mat downy to floccose in the first two weeks, becoming woolly in the third week, white; advancing zone superficial; margin uneven; odor earthy; reverse unchanged.

Micromorphological characters - Aerial mycelium: hyphae 1.5-6 $\mu \mathrm{m}$ diam., hyaline, sometimes with granulose refringent contents, thin and thick-walled (the thick-walled hyphae have refringent walls and non-staining lumen), branched, septate, with clamp connections or septae simple, with short branches, anastomoses present, sarco-hyphae present, as inflated hyphae with granulose refringent contents, some hyphae with a capitate apex; arthrospores and chlamydospores absent. Advancing zone: hyphae 1-4 $\mu \mathrm{m}$ diam., hyaline, sometimes with granulose contents, thin or thick-walled, branched, septate, with clamp connections, with short branches, anastomoses present, flexuose hyphae abundant; chlamydospores present (rare, observed in one isolate), globose, thin or thick-walled, with granulose contents, intercalar.

Material studied - strain 001-09, vegetative isolation from spore print of basidiome; growing on dung (Brazil, Rio Grande do Sul, Bagé, 21 March 2009, P.S. Silva 202/09 ICN 154231).

Deconica horizontalis (Bull.) Noordel.

Figs 2, 7 1-v

Macromorphological characters $-100 \%$ of plate covered by the $7^{\text {th }}$ day; mat downy to woolly, with some dense spots as from the second week, white; advancing zone superficial; margin uneven; odor strongly as antiseptic; reverse unchanged.

Micromorphological characters - Aerial mycelium: hyphae 1-7 $\mu \mathrm{m}$ diam., hyaline, frequently presenting oily contents, thin and thick-walled, branched, septate, with clamp connections or septate simple, multiple clamps present, with short branches, anastomoses present; arthrospores absent, chlamydospores present in one isolate, ellipsoid, thin-walled, with granulose contents. Advancing zone: hyphae 1.5-6 $\mu \mathrm{m}$ diam., hyaline, with oily contents, thin or thick-walled, branched, septate, with clamp connections, multiple clamps present, anastomoses present, innumerous short branches and flexuose hyphae; arthrospores and chlamydospores absent. 

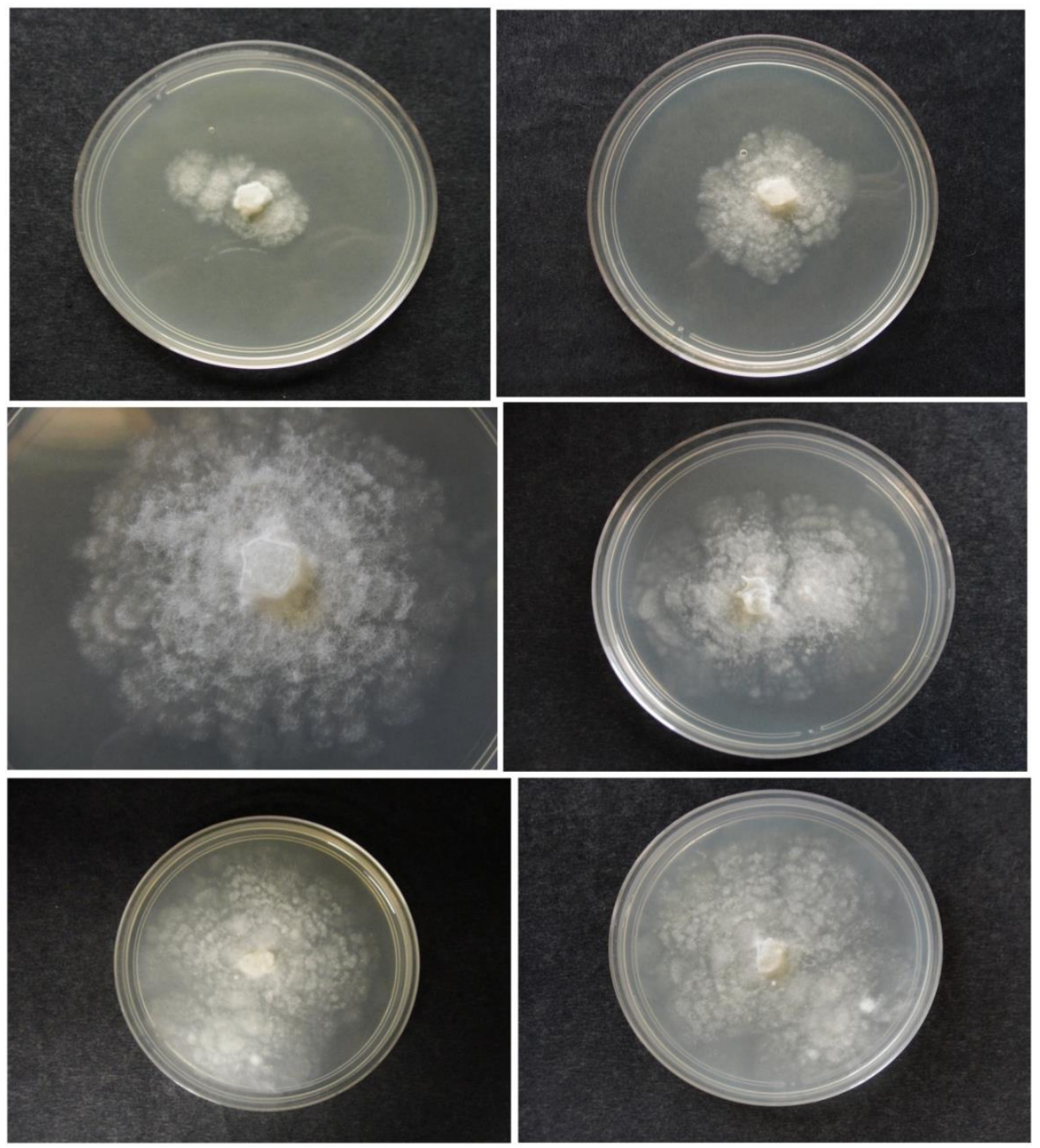

Fig. 1 - Deconica coprophila. Mycelial growth during the six weeks $\left(1^{\text {st }}\right.$ to $6^{\text {th }}$ week from left to right).

Material studied - strain 002-10, vegetative isolation from spore print of basidiome; growing on decayed wood (Brazil, Rio Grande do Sul, Santa Maria, 14 May 2010, P.S. Silva 253/10 ICN 154677).

Deconica neorhombispora (Guzmán) P.S. Silva \& Ram.-Cruz

Figs 3, 8a-i

Macromorphological characters $-35 \%$ of plate covered by the $7^{\text {th }}$ day (plates not completely covered during the six weeks, reaching $77 \%$ in the last week); mat downy, white; advancing zone superficial; margin uneven; odor musty; reverse unchanged.

Micromorphological characters - Aerial mycelium: hyphae 2-6.5 $\mu \mathrm{m}$ diam., hyaline or with granulose contents, thin or thick-walled, some hyphae with irregularly thick and refractive walls, and some with crystals on the walls, branched, septate, with clamp connections, but also septate simple, with multiple clamps, with innumerous short branches, forming a plectenchyma, anastomoses present, some isolate presenting cystidia, digitate, thick-walled; chlamydospores present, globose to ellipsoid, thin or thick-walled, terminal or intercalary. Advancing zone: hyphae 2-5 $\mu \mathrm{m}$ diam., hyaline, with or without oily contents, thin-walled, branched, septate, with clamps connections or septate simple, multiple clamps present, with anastomoses, flexuose hyphae abundant; chlamydospores present (in two isolates), globose to ellipsoid, thin-walled, with or without granulose contents, terminal or intercalary. 

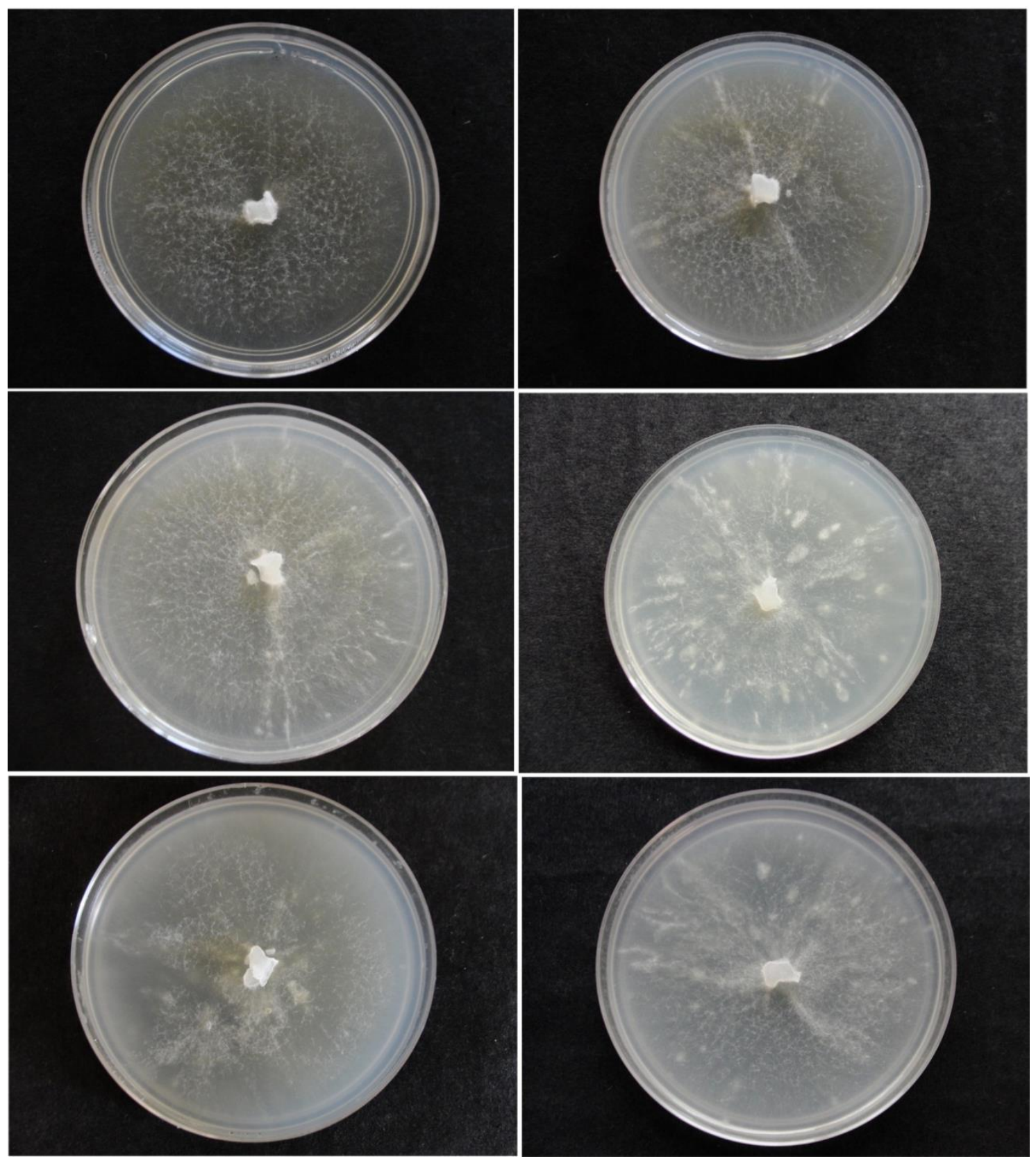

Fig. 2 -Deconica horizontalis. Mycelial growth during the six weeks.

Material studied - strain 003-09, vegetative isolation from spore print of basidiome, growing on decayed wood (Brazil, Rio Grande do Sul, Morrinhos do Sul, 4 October 2009, P.S. Silva 238/09 ICN 154351).

\section{Deconica sp.}

Figs $4,8 j-q$

Macromorphological characters $-68 \%$ of plate covered by the $7^{\text {th }}$ day, with plates completely covered as from the second week; mat downy, white, with concentric zones; advancing zone superficial; margin uneven; odor fruity; reverse unchanged.

Micromorphological characters - Aerial mycelium: hyphae 2-6 $\mu \mathrm{m}$ diam., hyaline, with oily contents, thin or thick-walled, with refringent walls, branched, septate, with clamp connections. multiple clamps present, with short branches and nodules, forming a plectenchyma, anastomoses present; arthrospores and chlamydospores absent. Advancing zone: hyphae 2.5-5 $\mu \mathrm{m}$ diam., hyaline, branched, septate, with clamp connections or septate simple, multiple clamps present, with short branches and nodules, flexuose hyphae abundant; chlamydospores present (rare, in one isolate), globose to ellipsoid, thin-walled, with granulose contents. 

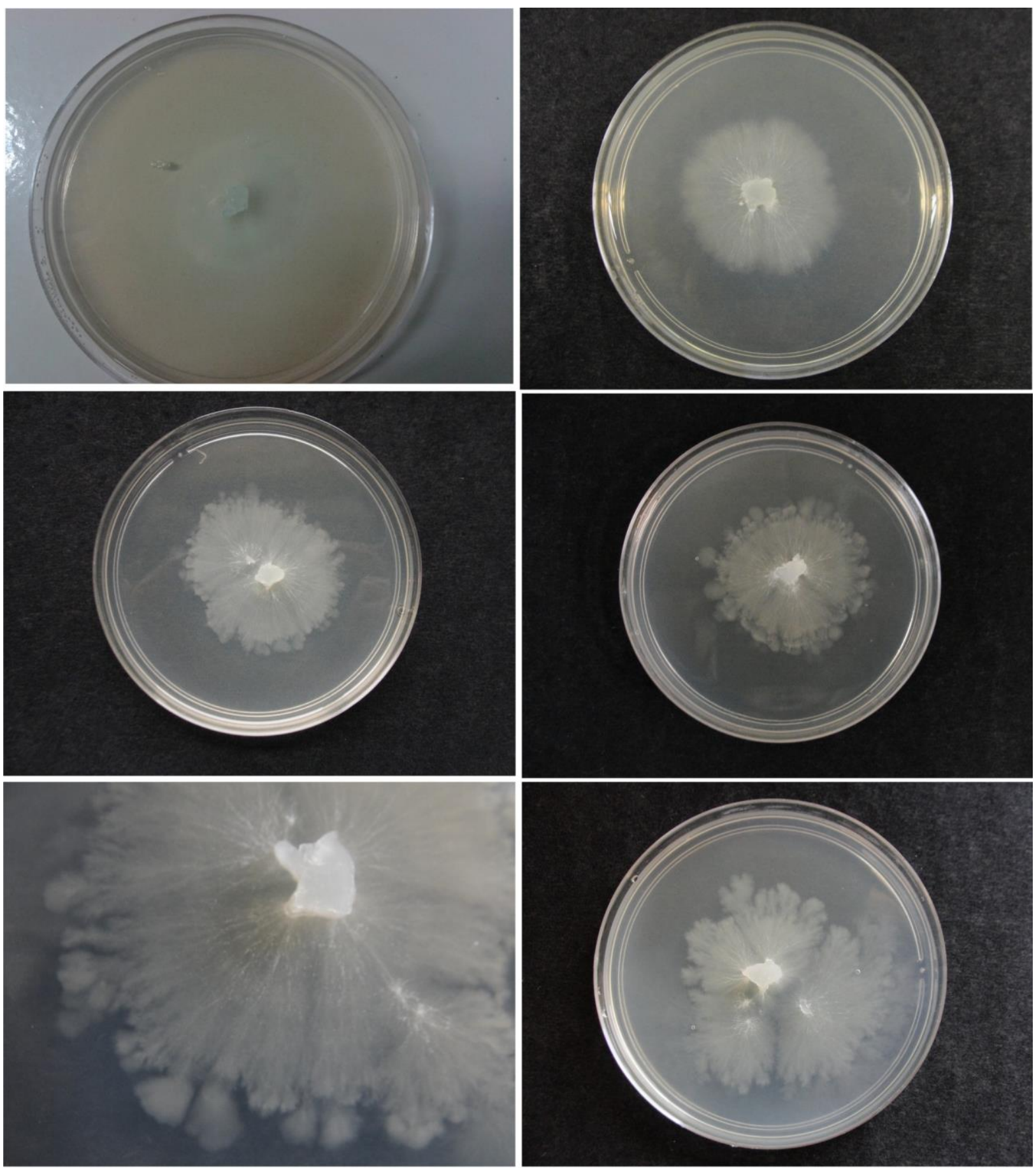

Fig. 3 - Deconica neorhombispora. Mycelial growth during the six weeks.

Material studied - strain 004-09, vegetative isolation from spore print of basidiome, growing among mosses (Brazil, Rio Grande do Sul, Derrubadas, 17 September 2009, P.S. Silva 235/09 ICN 154348).

Note - This species is similar to D. inquilina (Fr.) Romagn. from which differs by smaller basidiospores and cheilocystidia, and the presence of pleurocystidia.

Psilocybe cubensis (Earle) Singer

Figs $5,9 \mathrm{a}-\mathrm{h}, 10 \mathrm{a}-\mathrm{d}$

Macromorphological characters $-64 \%$ of plate covered by the $7^{\text {th }}$ day, with plates completely covered in two weeks; mat downy to woolly, with some dense spots as from the third week, white; presence of rhizomorphs in some isolates; advancing zone superficial; margin uneven; odor as "fungus"; reverse unchanged. 

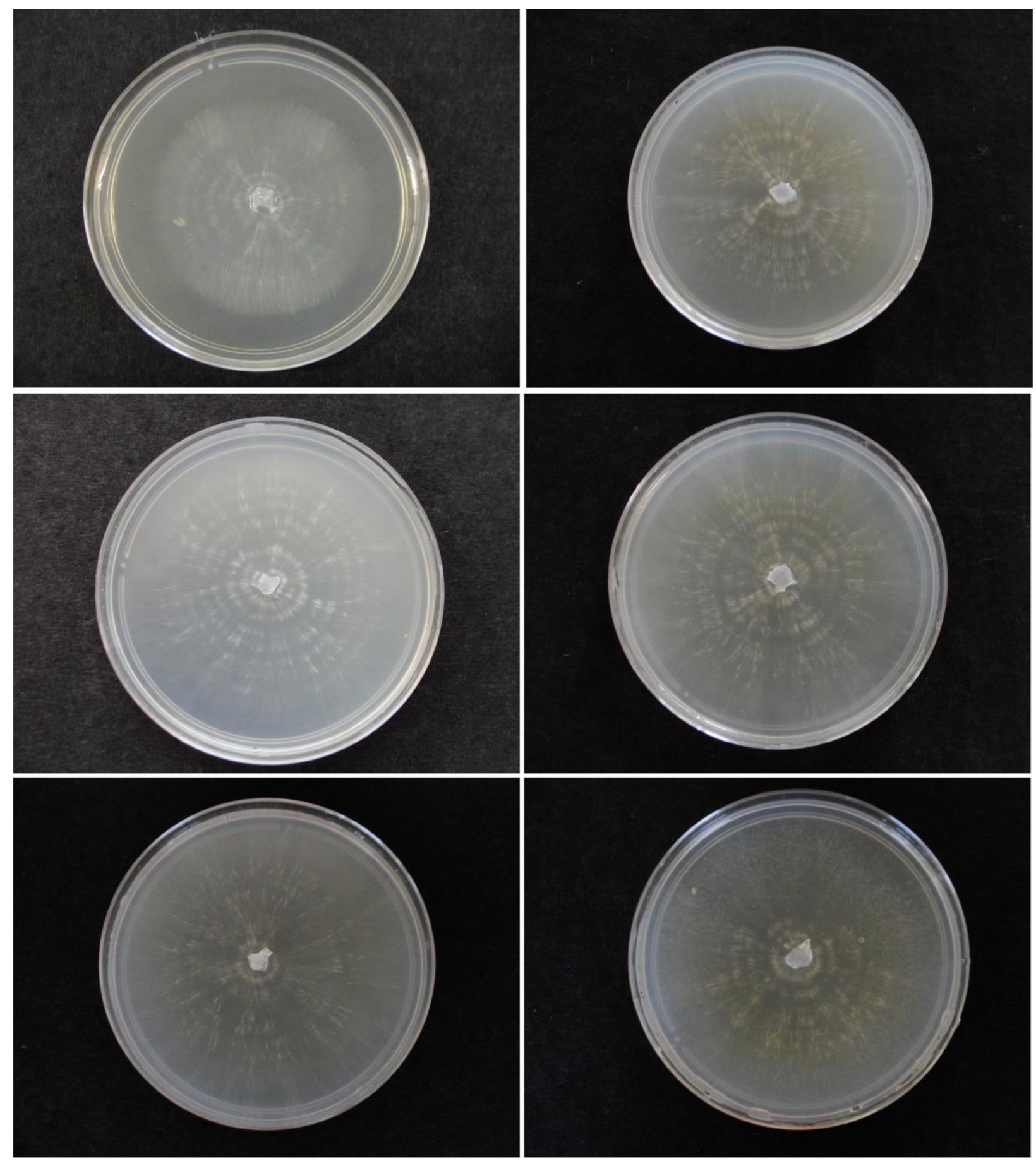

Fig. 4 - Deconica sp. Mycelial growth during the six weeks.

Micromorphological characters - Aerial mycelium: hyphae 2-4 $\mu \mathrm{m}$ diam., hyaline, thin or thick-walled (some hyphae are thick-walled with refringent walls and non-staining lumen), branched, septate, with clamp connections, sarco-hyphae present, as inflated, thin-walled, with granulose contents hyphae, anastomoses present; chlamydospores present, globose, thin or thickwalled, with granulose contents, intercalar. Advancing zone: hyphae 2-4 $\mu \mathrm{m}$ diam., hyaline, thin or thick-walled (refringent thick walls with non-staining lumen), branched, septate, with clamp connections, sarco-hyphae present, anastomoses present, and flexuose hyphae abundant; arthrospores and chlamydospores absent.

Material studied - strain 005-09, vegetative isolation from spore print of basidiome, growing on dung (Brazil, Rio Grande do Sul, Bagé, 21 March 2009, P.S. Silva 200/09 ICN 154229). 


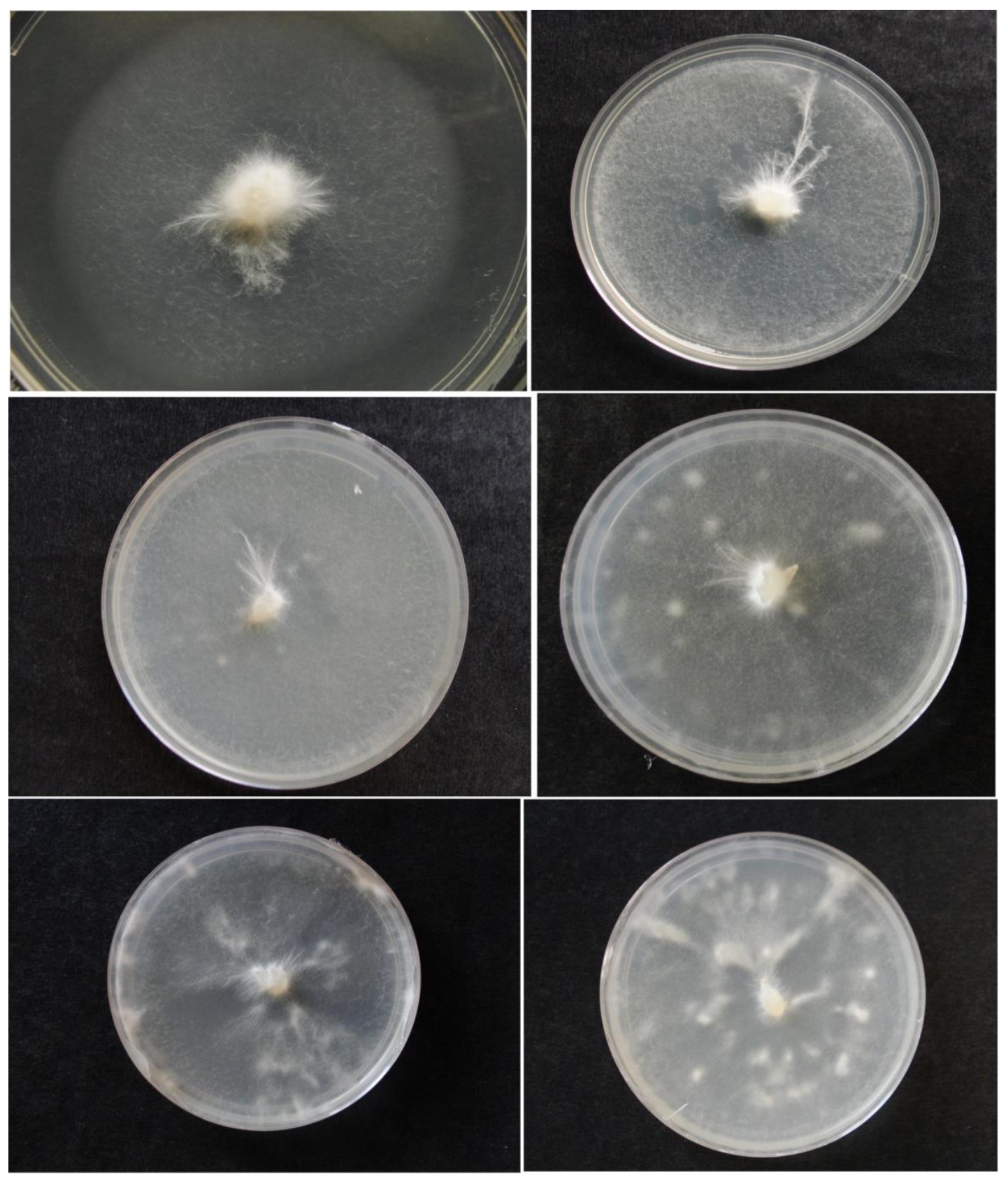

Fig. 5 - Psilocybe cubensis. Mycelial growth during the six weeks.

Stropharia venusta P.S. Silva, Cortez \& R.M. Silveira

Figs 6, 9i-1, 10e-f

Macromorphological characters $-21 \%$ of plates covered by the 7 th day, with plates completely covered in the $6^{\text {th }}$ week; mat cottony, white; advancing zone superficial; margin uneven; odor earthy; reverse unchanged.

Micromorphological characters - Aerial mycelium: hyphae 2-4 $\mu \mathrm{m}$ diam., hyaline, thin or thick-walled (the thick walls are refractive, with non-staining lumen), branched, septate, clamp connections not observed, anastomoses present, acanthocytes present; arthrospores and chlamydospores absent. Advancing zone: hyphae 1-3 $\mu \mathrm{m}$ diam., hyaline, thin or thick-walled hyphae with non-staining lumen, branched, septate, clamp connections not observed, with flexuose hyphae, acanthocytes present; chlamydospores present, globose to ellipsoid, thin or thick-walled, with or without granulose contents, terminal and intercalar.

Material studied - strain 006-09, vegetative isolation from spore print of basidiome, growing on decayed wood (Brazil, Rio Grande do Sul, São Francisco de Paula, 29 May 2009, P.S. Silva 265/12 ICN). 

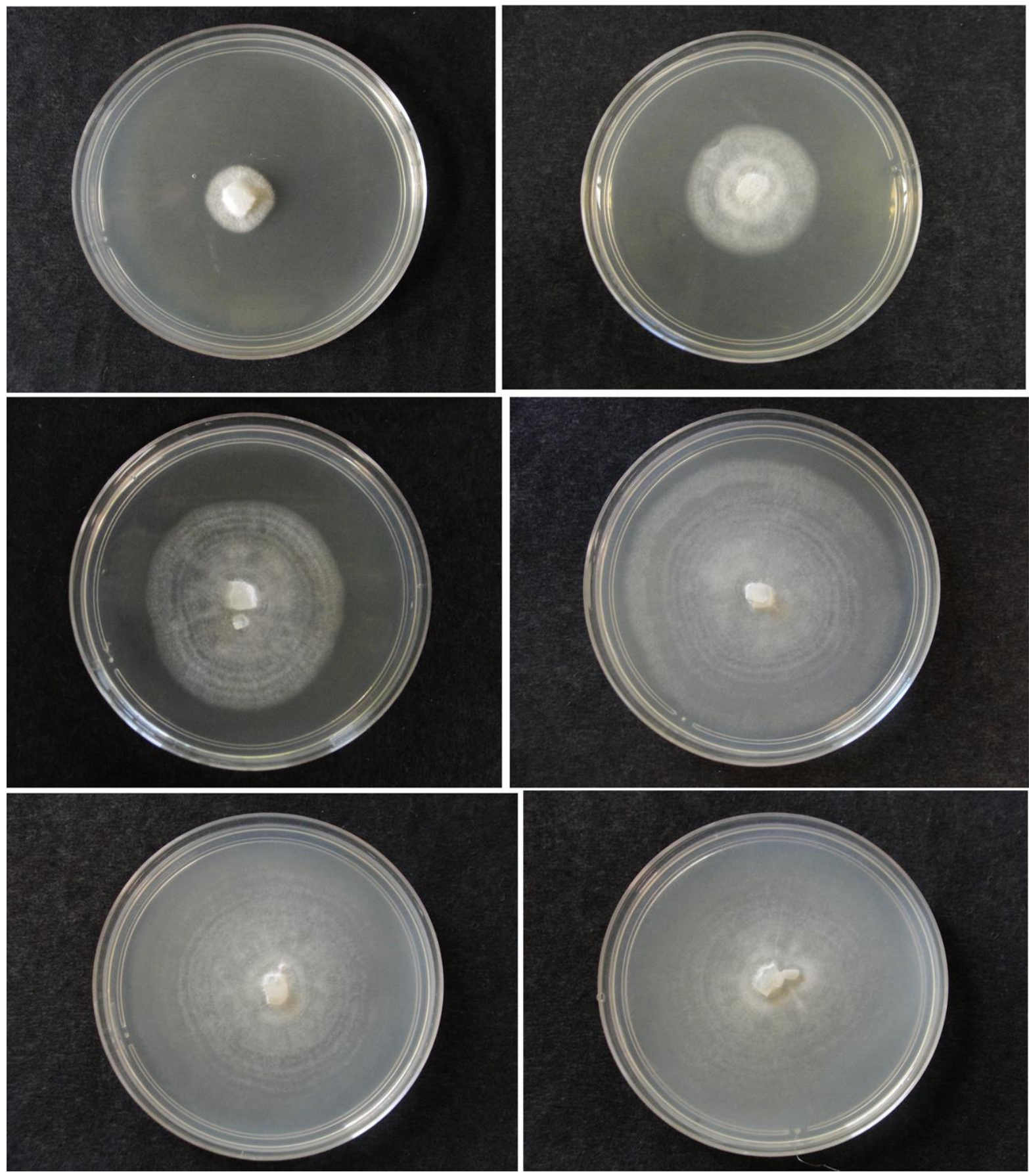

Fig. 6 - Stropharia venusta. Mycelial growth during the six weeks.

\section{Discussion}

The macro-morphology of the cultures studied present some remarkable differences. Deconica neorhombispora and D. coprophila present the mat margin irregular and slow growth, while D. horizontalis, Deconica sp. and P. cubensis have their mat margin regular and faster growth. Stropharia venusta presents a different mat texture, being cottony, not translucent, while the Psilocybe sensu lato studied strains are all downy or woolly, and translucent.

In basidiome in situ, a bluing coloration can be observed, with material bruising or aging, as result of alkaloids oxidation, and it has been used for differing Psilocybe species from Deconica. This coloration change can be also observed in cultures, but it was not observed during the six weeks in $P$. cubensis, although the authors have observed this reaction in older strains of this species. 

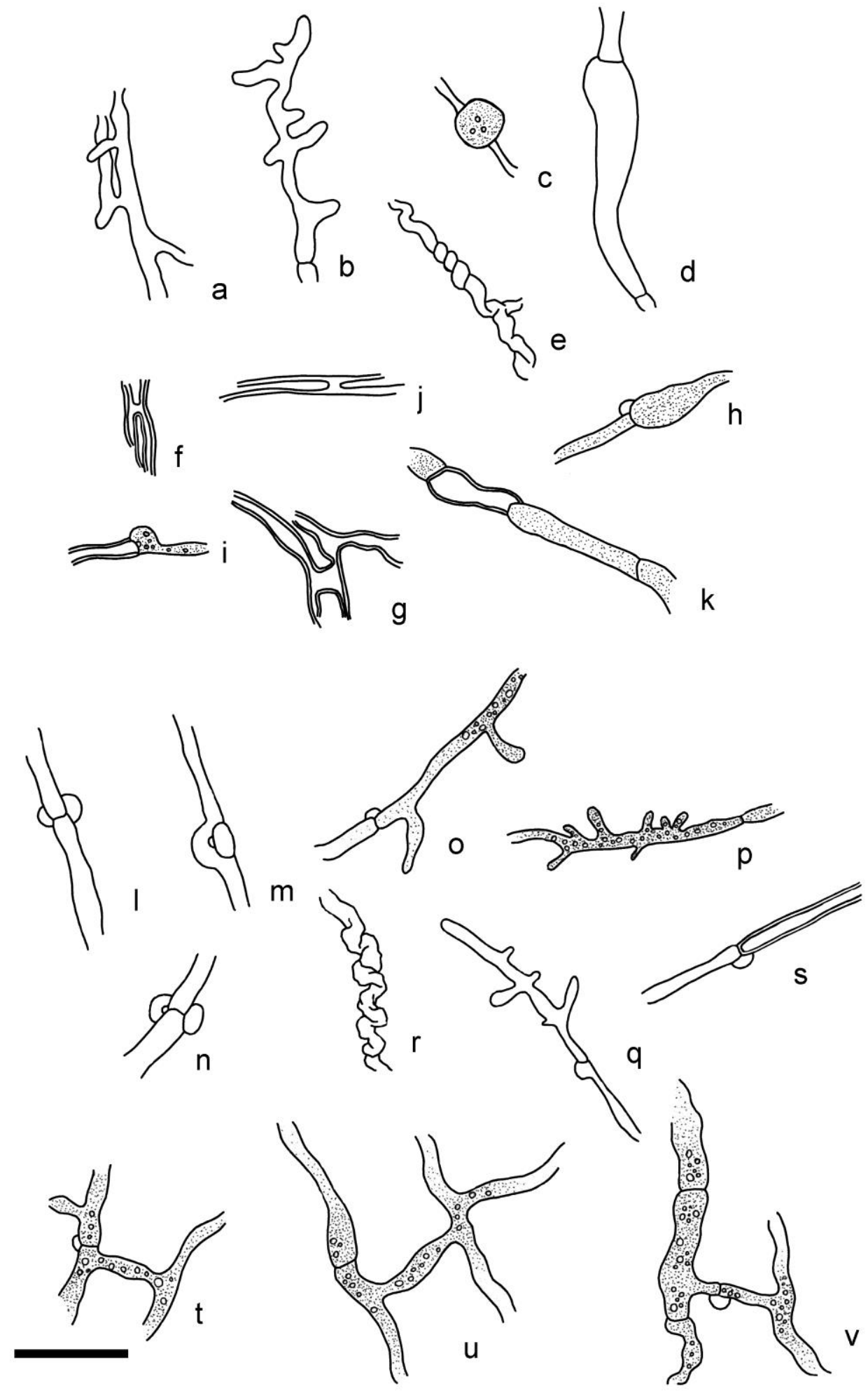

Fig. 7 - Deconica coprophila (a-k). a, b. Hyphae with short branches. c. Intercalar chlamydospore. d. Sarco-hypha. e. Flexuose hypha. f, g. Thick-walled hyphae with anastomose. h. Septate inflate and fibulate hypha. i. Fibulate thin-walled hypha and non-staining lumen, thick-walled hypha. j. Thin-walled hypha with anastomose. k. Staining and non-staining hypha. Deconica horizontalis (1v). 1, m. Multiple clamps. o-q. Hyphae with short branches. r. Flexuose hypha. s. Thin and thickwalled hyphae. $\mathrm{t}-\mathrm{v}$. Anastomoses. Bar $=10 \mu \mathrm{m}$. 

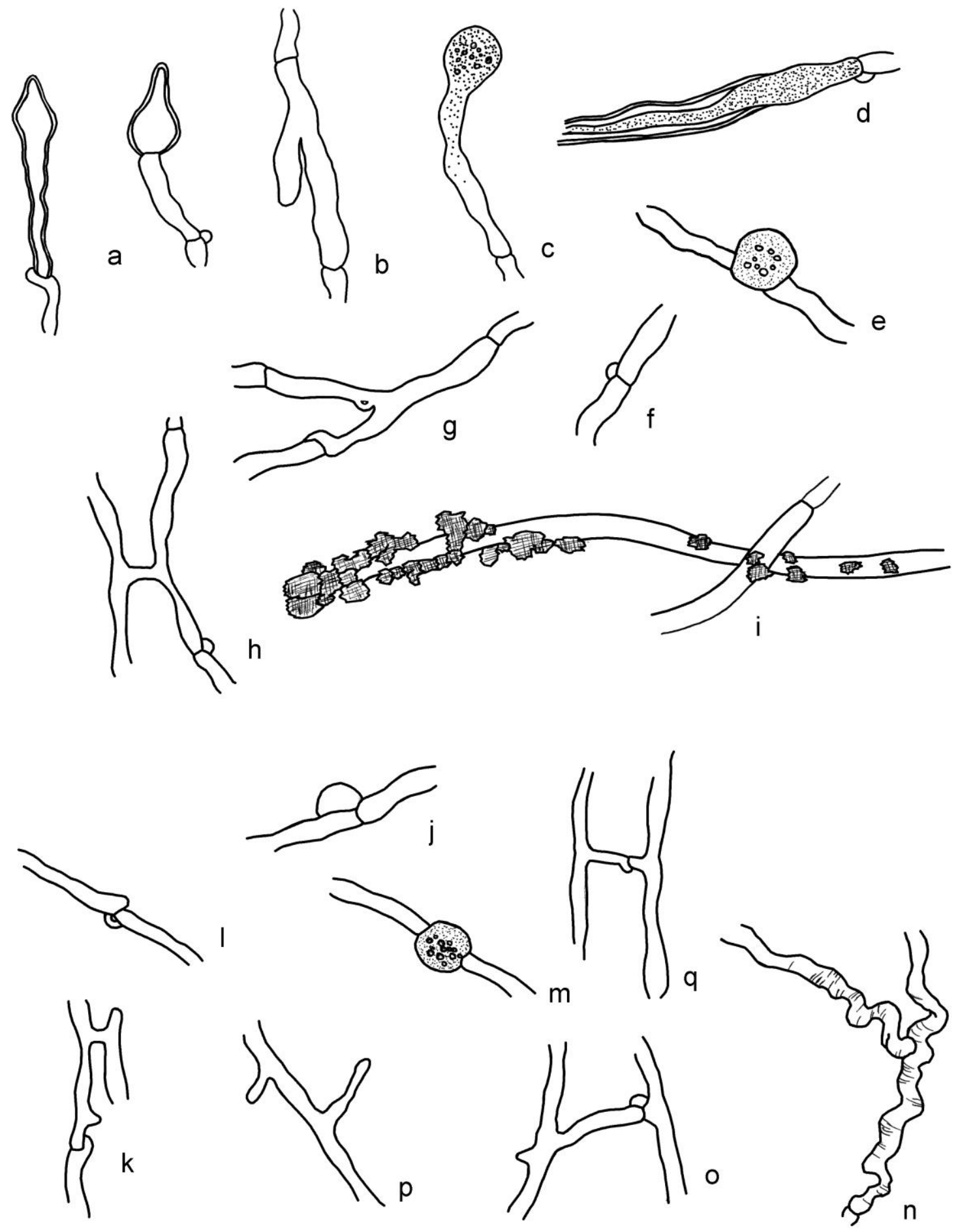

Fig. 8 - Deconica neorhombispora (a-i). a. Mycelial cystidia b. Branched hypha. c. Terminal chlamydospore. d. Fibulate hypha irregularly thick-walled. e. Intercalar chlamydospore. f. Fibulate hypha. g. Branched fibulate hypha. h. Anastomose. i. Hyphae with crystals. Deconica sp. (j-q). j. Inflate fibulae. k. Anastomose. 1. Fibulate hypha. m. Intercalar chlamydospore. n. Flexuose hypha. o. Hypha with anastomose and short branch. p. Hypha with branches. q. Anastomose. Bar $=10 \mu \mathrm{m}$. 

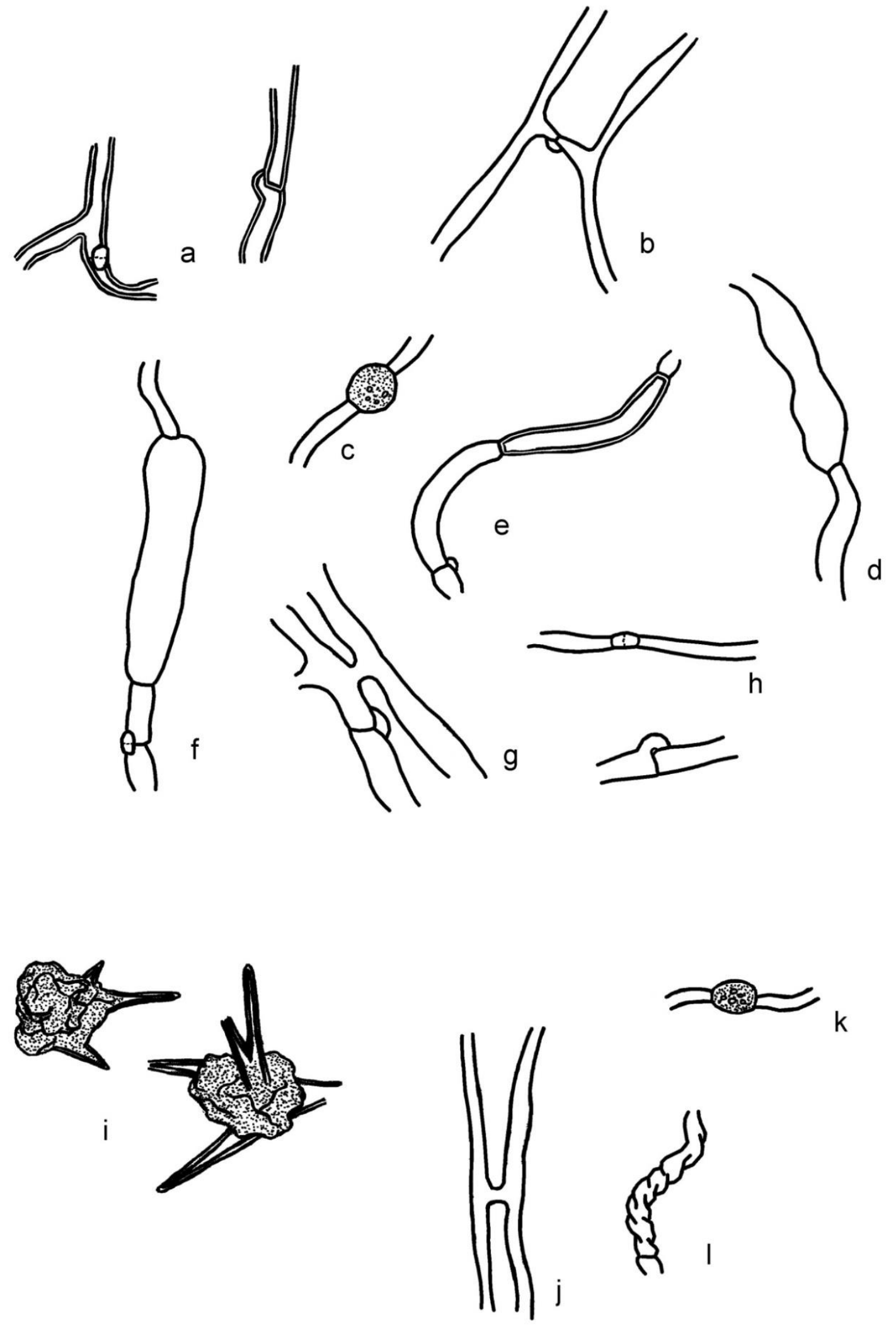

Fig. 9 - Psilocybe cubensis $(\mathrm{a}-\mathrm{h})$. a. Fibulate thick-walled hyphae b. Anastomose. c. Intercalar chlamydospore. d. Sarco-hypha. e. Thin and thick-walled hyphae. f. Sarco-hypha formation. g. Anastomose. h. Fibulate hyphae. Stropharia venusta (i-1). i. Acanthocytes. J. Anastomose. K. Intercalar chlamydospore. 1. Flexuose hypha. Bar $=10 \mu \mathrm{m}$. 


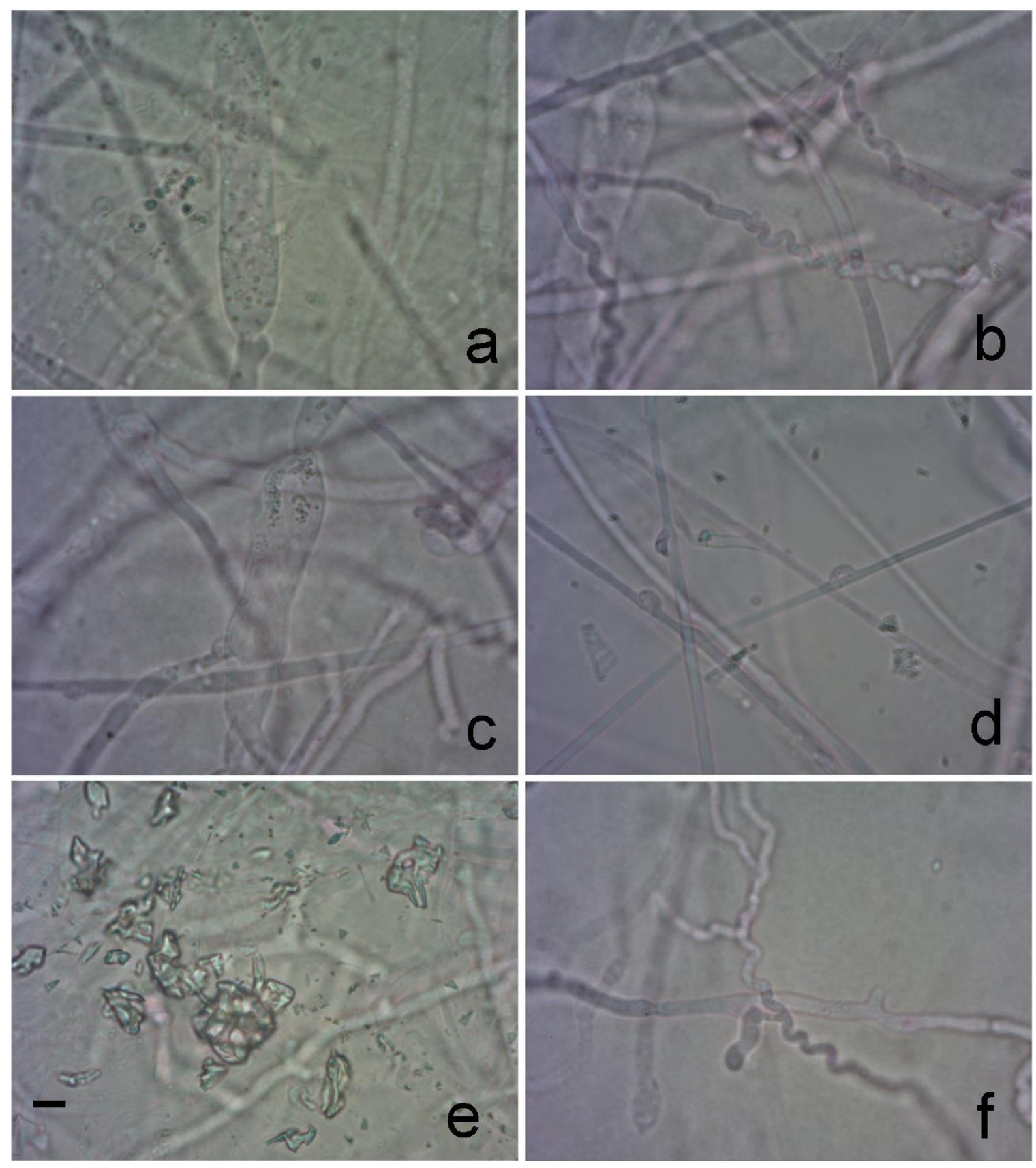

Fig. 10 - Psilocybe cubensis (a-d). a. Sarco-hypha in aerial mycelium b. Flexuose hyphae in advancing mycelium c. Sarco-hypha in advancing mycelium d. Fibulate hyphae in advancing mycelium. Stropharia venusta (e-f). e. Acanthocytes f. Flexuose hyphae in advancing mycelium. Bar $=5 \mu \mathrm{m}$.

Some micromorphological characters observed, such as presence of anastomoses on hyphae, are rather constant in all studied strains, as well as in other genera (Buchalo et al. 2011), and probably do not represent taxonomic relevance. Although just one studied species presented crystals on some hyphae walls, these are also considered no valuable characters, once that oxalic acid is naturally formed as metabolite of the Krebs cycle (Molitoris et al. 1996).

Size and shape of arthrospores and chlamydospores have been considered helpful for species identification in some genera (Fausto-Guerra et al. 2002). In the present work, the strains did not present arthrospores in the six weeks, but they did present chlamydospores. However, these structures are very similar among the studied species, regarding their size, shape and wall thickness, giving no clue for delimitating species. Meanwhile, they may present some value in larger sampling, for delimitating species group. 
Mycelial cystidia have been observed just in D. neorhombispora and seem to be rather characteristic, utriform, with a narrow or large base, and thick-walled. This can be a good specific character, as have been already discussed by Nobles (1965), who observed mycelial cystidia in some species of her study. Walther \& Weiß (2008) also observed cyanophilous mycelial cystidia in Hypholoma and Stropharia species, but there are few records of these structures in fungal culture studies. Additionally, sarco-hyphae seem to be uncommon in mycelial studies. Kirk et al. (2001) characterized as sarco-hyphae long, inflated hyphae. Following this concept we concluded that the structures observed here may be included in this classification and provide a relevant taxonomic character.

Gilmore (1926) observed arthrospores in D. coprophila, but these were not observed in the studied strain. It is probable that the presence or absence of these structures is variable among different strains. Likewise, Buchalo et al. (2009) observed arthroconidia and crystals on hyphae in $P$. cubensis, which were not observed in the studied strain in this work.

The presence of acanthocytes in Stropharia mycelium in culture has been first observed by Farr (1980) and recently by Walther \& Weiß (2008), and these structures are considered a good generic character (Cortez \& Silveira 2007, Noordeloos 2011). Stropharia venusta presents abundant acanthocytes in mycelium. Acanthocytes are spine shape structures, with refringent thick walls, and are known to function as nematode-trapping (Luo et al. 2006).

\section{Acknowledgements}

The authors thank to Conselho Nacional de Desenvolvimento Científico e Tecnológico (CNPq) for financial support. Dr. Gastón Guzmán is thanked for kindly providing literature.

\section{References}

Buchalo AS. 1988 - Higher Edible Basidiomycetes in Pure Culture. Nauk. Dumka, Kiev.

Buchalo AS, Mykchaylova O, Lomberg M, Wasser SP. 2009 - Microstructures of vegetative mycelium of macromycetes in pure culture. Alterpress, Kiev.

Buchalo AS, Solomon PW, Mykhaylova BO, Bilay VT, Lomberg ML. 2011 - Taxonomical significance of microstructures in pure cultures of macromycetes. In: Mushroom Biology and Mushroom Products; Proceedings of the $7^{\text {th }}$ International Conference on Mushroom Biology and Mushroom Products (ICMBMP7). Arcachon, France.

Cortez VG \& Silveira RMB. 2007 - A new species of Stropharia with hymenial acanthocytes. Mycologia 99 (1), 135-138.

Dubovoy C, Herrera T. 1967 - Estudio morfológico de micelios de Psilocybe caerulescens en diversos medios líquidos de cultivo. Anales del Instituto de Biología UNAM (serie Botánica) 38, 11-150.

Dubovoy C, Herrera T. 1968 - Morfogénesis de fíbulas, I. Desdicariotización en diversos medios líquidos de cultivo. Anales del Instituto de Biología UNAM (serie Botánica) 39, 45-76.

Farr D. 1980 - The acanthocyte, a unique cell type in Stropharia (Agaricales). Mycotaxon 11, 241249.

Fausto-Guerra S, Guzmán-Dávalos L, Velázquez-Hueso JC. 2002 - Cultural studies of Gymnopilus species (Cortinariaceae, Agaricales). Mycotaxon 84, 429-444.

Gilmore KA. 1926 - Culture studies in Psilocybe coprophila. Botanical Gazette 81, 419-432.

Heim R, Cailleux R, Wasson RG, Thévenard P. 1963 - Nouvelles investigations sur les champignos hallucinogènes. Archives du Muséum National d'Histoire Natural 7, 115-218. (reprinted in 1967 by the Muséum National d'Histoire Natural, Paris).

Heim R, Wasson G, Hofmann A, Cailleux R, Cerletti A, Brack A, Kobel H, Delay J, Pichot P, Lemperière Th., Nicolas-Charles PJ. 1957 - Les champignons hallucinogens du Mexique. Études ethnologiques, taxinomiques, biologiques, physiologiques et chimiques. Renée Gyssels, Paris.

Jacobsson S. 1989 - Studies on Pholiota in culture. Mycotaxon 36 (1), 95-145. 
Kirk, PM, Cannon, PF, Minter, DH, Stalpers JA. 2001 - Ainsworth and Bisby's Dictionary of Fungi. CAB International, Wallingford.

Luo H, Li X, Li G, Pan Y, Zhang K. 2006 - Acanthocytes of Stropharia rugosoannulata function as a nematode-attacking device. Applied Environmental Microbiology 72 (4), 2982-2987. doi:10.1128/AEM.72.4.2982-2987.2006.

Molitoris PH, Buchalo AS, Grigansky AP. 1996 - Studies of the vegetative mycelium in the genus Agaricus L.: Fr. emend. Karst. In: Botany and mycology for the next millennium. Institute of Botany, Kiev.

Moncalvo JM, Vilgalys R, Redhead SA, Johnson JE, James TY, Aime MC, Hoffstetter V, Verduin SJW, Larsson E, Baroni TJ, Thorn RG, Jacobsson S, Clémençon H, Miller Jr. OK. 2002 One hundred and seventeen clades of euagarics. Molecular Phylogenetics and Evolution 23, 357-400. doi: 10.1016/S1055-7903(02)00027-1.

Nobles MK. 1965 - Identification of cultures of wood-inhabiting Hymenomycetes. Canadian Journal of Botany 43(9), 1097-1139.

Noordeloos ME. 2011 - Strophariaceae s.l. Fungi Europeai. Candusso, Alassio.

Singer R. 1986 - The Agaricales in modern taxonomy. Koeltz Scientific Books, Koenigstein.

Stalpers JA. 1978 - Identification of wood-inhabiting Aphyllophorales in pure culture. Studies in Mycology 16, 1-248.

Stamets P. 2000 - Growing gourmet and medicinal mushrooms. Ten Speed Press, Berkeley.

Walther G, Wei $\beta$ M. 2008 - Anamorphs in the Strophariaceae (Basidiomycota, Agaricales). Botany 86, 551-566. doi: 10.1139/B08-036.

Watling R. 1971 - Polymorphism in Psilocybe merdaria. New Phytologist 70, 307-326. 